\title{
The prognosis of cases with massive subretinal hemor- rhage after photodynamic therapy
}

\author{
Shingo Matsushita, Takeshi Naito, Masaru Takebayashi, Hiroyuki Sato, and \\ Hiroshi Shiota \\ Department of Ophthalmology, Institute of Health Biosciences, the University of Tokushima Graduate \\ School, Tokushima, Japan
}

\begin{abstract}
Purpose : To investigate cases with massive subretinal hemorrhage after photodynamic therapy(PDT).

Subjects and Methods: We studied four cases(3 men and 1 woman, mean 80.5 yeas old) with massive subretinal hemorrhage after PDT about type of disease, spot size, period to the onset of hemorrhage, visual acuity (VA) before and after PDT.

Results : Four cases consisted of one with age-related macula degeneration (AMD) and 3 with polypoidal choroidal vasculopathy (PCV). The average spot size of PDT was $5525 \mu \mathrm{m}$. Two patients underwent the second PDT about 3 months after the initial PDT. Four periods to the onset of hemorrhage were $22,27,137$, and 208 days respectively. The latter 2 cases underwent PDT twice, and the periods were the days from the initial PDT. Two patients among four underwent vitrectomy. Average VA before PDT was 0.20, and the final one was 0.02 after PDT.

Conclusions : PDT has a risk to cause massive subretinal hemorrhage leading to grave visual disturbance. Especially PDT for PCV seems to have more risk. Therefore we need to inform patients about the risk before PDT, since treating patients with massive subretinal hemorrhage is very difficult J. Med. Invest. 55 : 231-235, August, 2008
\end{abstract}

Keywords : $P D T, A M D, P C V$, subretinal hemorrhage, risk

\section{INTRODUCTION}

Photodynamic therapy (PDT) was approved as a treatment for age-related macular degeneration (AMD) in Japan since May, 2004. The number of institutions dealing with PDT and cases actually done have been increasing year by year. PDT has been regarded as the treatment of choice for AMD now. Recently many studies on PDT were reported and some studies mentioned that PDT has shown

Received for publication May 1, 2008 ; accepted June 10, 2008.

Address correspondence and reprint requests to Takeshi Naito, Department of Ophthalmology, Institute of Health Biosciences, the University of Tokushima Graduate School, Kuramoto-cho, Tokushima 770-8503, Japan and Fax : +81-88-631-4848. more effective than the results of The Japanese AMD Trial, an open-label, multicenter, prospective, and noncontrolled study (1). On the other hand, the number of reports on the complications of PDT has been increasing (2-5). Massive subretinal hemorrhage, one of the side effects after PDT, might lead to grave visual disturbance. However the cause or mechanism of subretinal hemorrhage after PDT is still unclear. We report four cases with massive subretinal hemorrhage after PDT.

\section{PATIENTS AND METHODS}

This study consisted of retrospective consecutive series of patients who were treated with PDT for 
AMD at our university hospital from October 2004 to September 2006. All patients gave their informed consent to be treated with PDT. A total of 4 cases with massive subretinal hemorrhage out of 149 cases undergone PDT were investigated carefully. All patients underwent pretreatment ophthalmological examinations including visual acuity (VA), fluorescein angiography (FA), indocyanin green angiography (IA), and an optical coherence tomograph (OCT, Stratus OCT3000 ; Carl Zeiss, Dublin, CA, USA). We also studied spot size, period to the onset of hemorrhage, visual acuity before and after PDT. We defined as massive subretinal hemorrhage if the spread is more than the area of vasucular arcade of the retina.

\section{RESULTS}

Among 149 cases treated with PDT, 103 cases were AMD and 46 cases were polypoidal choroidal vasculopathy $(\mathrm{PCV})$. The four cases consisted of one with AMD and 3 with PCV. The incidence of massive subretinal hemorrhage is $3(6.5 \%)$ of 46 cases with PCV and one ( $0.9 \%)$ of 103 cases with AMD. Therefore, the incidence is much higher in the patients with PCV than the patients with AMD. The average spot size of PDT was $5525 \mu \mathrm{m}$. Two out of four patients underwent the second PDT about 3 months after the initial PDT. The periods to the onset of hemorrhage were $22,27,137$, and 208 days respectively. The latter 2 cases underwent PDT twice, and the period was calculated from the initial PDT. Two patients underwent vitrectomy. The average VA before PDT was 0.20 , and the final was 0.02 after PDT. The profiles of these four cases were shown in Table 1 . The following is a typical case.

\section{Case 1}

A 78-year-old woman was diagnosed as macular degeneration in her right eye four months before and followed up by a nearby doctor. Her visual acuity deteriorated gradually, then she was referred to our hospital on September 21, 2005. On examination, her visual acuities were 0.4 in the right and 0.7 in the left eye. Intraocular pressure was normal in both eyes and no abnormal findings were observed in the anterior segment and the ocular media. A subretinal hemorrhage, fibrin, hard exudate, and reddish-orange nodules were recognized in the right macula (Fig. 1). Fluorescein angiography (FA) showed leakage and hyperfluorescence at the lesion,

Table 1 The profiles of four cases with massive subretinal hemorrhage after PDT

\begin{tabular}{ccccccccc}
\hline Case & $\begin{array}{c}\text { Age } \\
\text { Sex }\end{array}$ & $\begin{array}{c}\text { Type of } \\
\text { disease }\end{array}$ & $\begin{array}{c}\text { Spot } \\
\text { size } \\
(\mu \mathrm{m})\end{array}$ & $\begin{array}{c}\text { Period to the } \\
\text { onset of } \\
\text { hemorrhage }\end{array}$ & $\begin{array}{c}\text { Visual acuity }{ }^{1} \\
\text { before PDT }\end{array}$ & $\begin{array}{c}\text { Visual acuity }^{1} \\
\text { after PDT }\end{array}$ & $\begin{array}{c}\text { Vitrec- } \\
\text { tomy }\end{array}$ & $\begin{array}{c}\text { Previous } \\
\text { disease }\end{array}$ \\
\hline 1 & 78 Female & PCV & 4800 & 22 days & 0.4 & 0.02 & Hyper-tension \\
Anemia
\end{tabular}

1)visual acuity is corrected eyesight

2)case 3 and 4 underwent PDT twice, and the days after initial the PDT are shown in parentheses

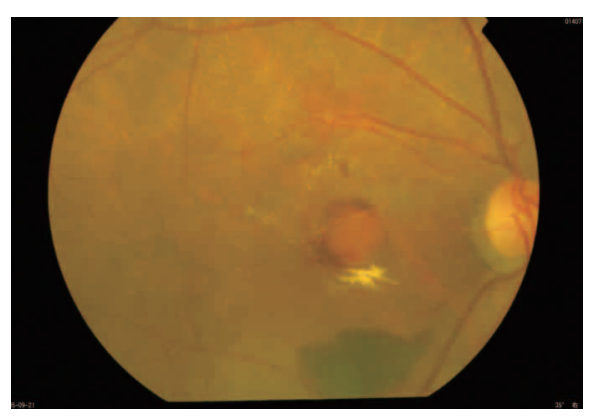

$\mathrm{RV}=(0.4)$

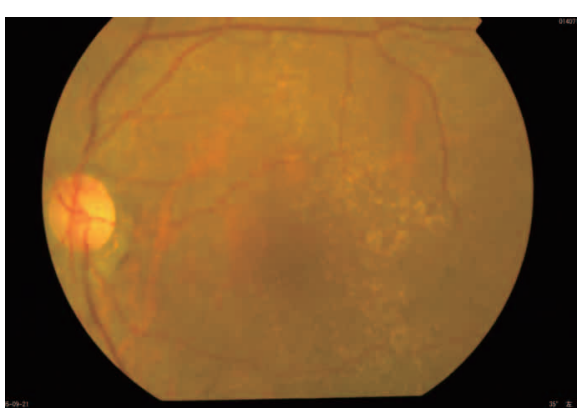

$L V=(0.7 p)$

Fig. 1 Clinical photograph before PDT showed a subretinal hemorrhage, fibrin, hard exudate, and reddish-orange nodules were recognized in the right macula 
showing classic choroidal neovascularization (CNV) (Fig. 2). Indocyanine green angiography (IA) showed multiple polypoidal choroidal vascular lesions (Fig. 3). She was diagnosed as PCV from these findings. PDT was performed with a 4800 $\mu \mathrm{m}$ spot size, as guided by the abnormalities shown in the FA on October, 28, 2005. No complications were recognized during the treatment. The patient complained of a rapid decrease in her right vision on 22 days after PDT. We fond the massive subreti-

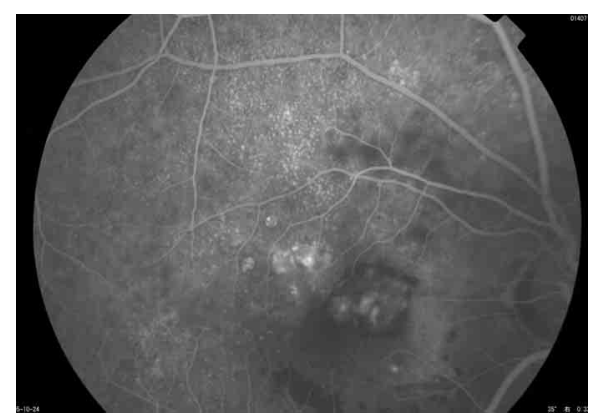

Early phase nal hemorrhage which spread more than the area of vasucular arcade of the retina in her right eye on November 30, 2005 (Fig. 4). Her right visual acuity decreased to 0.04 . She was followed up and treated with oral use of carbazochrome sodium sulfonate. Despite the absorption of the hemorrhage, fibrin deposition and organization of the hemorrhage were recognized. The final visual acuity became 0.02 .

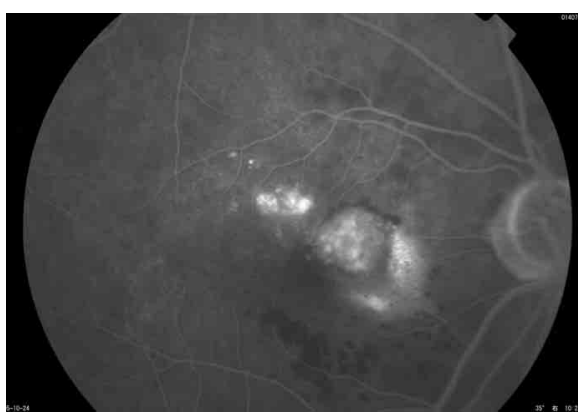

Late phase

Fig. 2 Fluorescein angiography before PDT showed leakage and hyperfluorescence at the lesion, showing classic choroidal neovascularization.

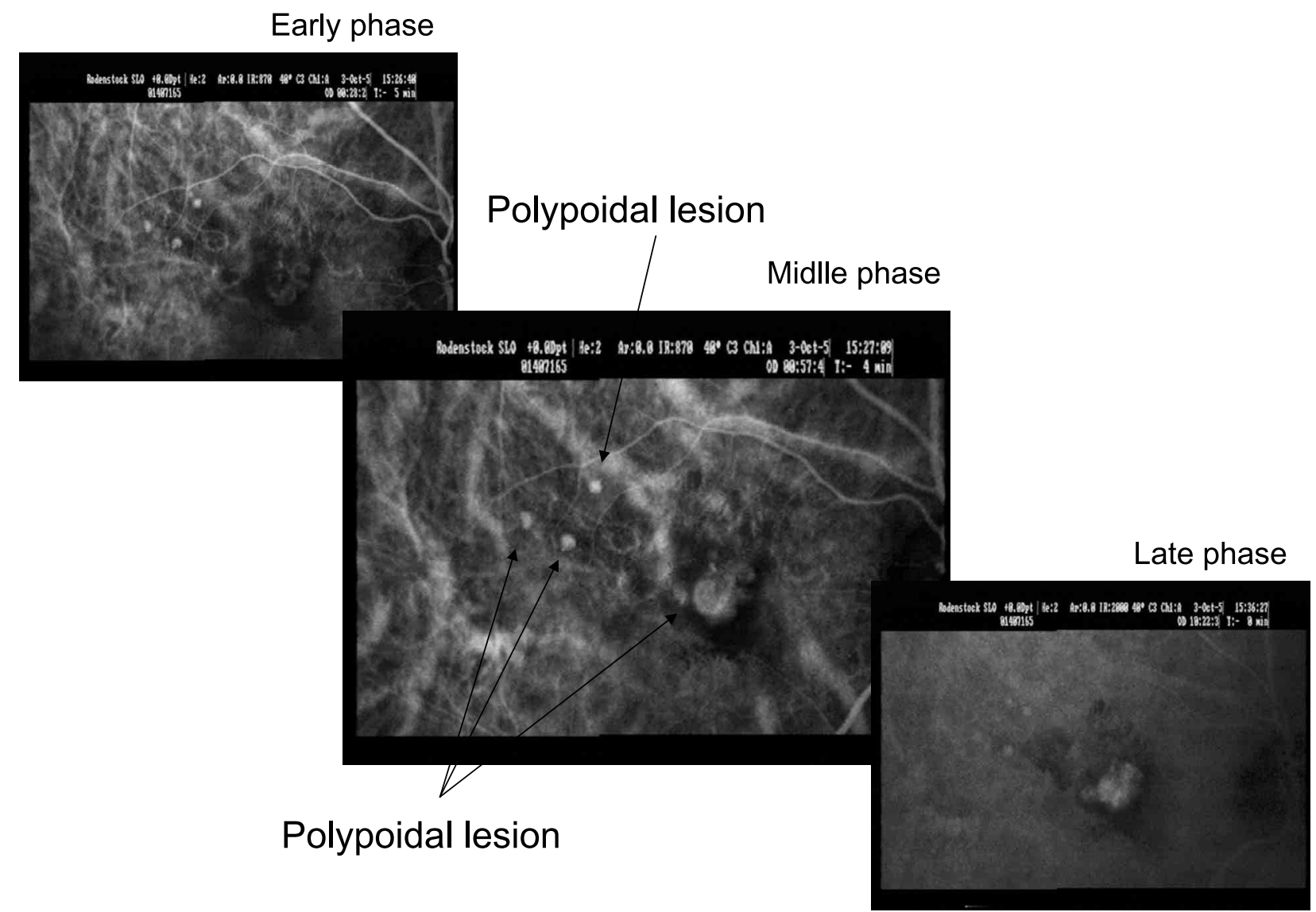

Fig. 3 Indocyanine green angiography showed multiple polypoidal choroidal vascular lesions. 


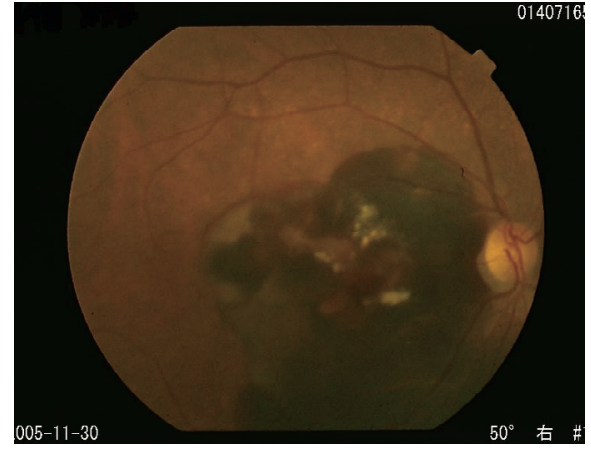

$\mathrm{RV}=(0.04)$

Fig. 4 Clinical photograph after PDT showed the massive subretinal hemorrhage which spread more than the area of vasucular arcade of retina.

\section{DISCUSSION}

Although our number is limited, three of 4 cases were PCV. The incidence of massive subretinal hemorrhage is $6.5 \%$ in the patients with PCV and almost same as the previous report (11). The incidence is much higher in the patients with PCV than the patients with AMD. Therefore, our study alarms that PDT for PCV seems to cause massive subretinal hemorrhage. Spot size of 4 cases was relatively large. Two out of four patients had massive subretinal hemorrhage after the second PDT, so care must be taken even if subretinal hemorrhage dose not appear after the initial PDT. But it is not clear whether PDT itself causes massive subretinal hemorrhage or not, because the periods to the onset of hemorrhage of thses 2 cases were long. Among Japanese the proportion of PCV among exudative AMD is large (6), and PDT for PCV has shown to be more effective than that for other types of AMD (7-10). This leads that we have more chance of PDT for PCV and the number of cases with subretinal hemorrhage after PDT will increase. PDT itself leads to inflammation at the exposure field and ischemia by angiopathic mechanism. The inflammation or ischemia produces vascular endothelial growth factor(VEGF) in the retina, and then angiogenesis or vascular permeability occurs. That may trigger subretinal hemorrhage. Larger spot size is likely to induce widespread inflammation and ischemia, and trigger subretinal hemorrhage. Recently, IA is more popular than FA in guiding a suitable laser spot size. This enables to treat by minimal greatest linear dimension (GLD) and to minimize inflammation and ischemia by PDT. But it is possible that we fail to cover lesions hiding under hemorrhage when PDT is delivered only as guided by the abnormalities shown by IA. Especially it is necessary to cover lesions like abnormal network of choroidal neovascularization in PDT for PCV, in order to prevent a recurrence or hemorrhage after PDT. From now on, we need comprehensively check lesions and conditions from findings not only of FA and IA, but also of OCT. Then custom-made treatment for each case can be done. We also should consider PDT combined with juxafoveal injection of triamcinolone acetonide or intravitreous injection of anti-VEGF antibodies.

\section{REFERENCES}

1. The Japanese Age-related Macular Degeneration Trial (JAT) Study Group : Japanese agerelated macular degeneration trial : 1 -year results of photodynamic therapy with verteporfin in Japanese patients with subfoveal choroidal neovascularization secondary to age-related macular degeneration. Am J Ophthalmol 136 : 1049-1061, 2003

2. Wachtlin J, Behme T, Heimann H, Kellner U, Foerster $\mathrm{MH}$ : Concentric retinal pigment epithelium atrophy after a single photodynamic therapy. Graefes Arch Clin Exp Ophthalmol $241: 518-521,2003$

3. Schmidt-Erfurth U, Schlotzer-Schrehard U, Cursiefen C, Michels S, Beckendorf A, Naumann GOH : Influence of photodynamic therapy on expression of vascular endothelial growth factor(VEGF), VEGF receptor3, and pigment epithelium-derived factor. Invest Ophthalmol Vis Sci $44: 4473-4480,2003$

4. Tzekov R, Lin T, Zhang K, Jackson B, Oyejide A, Orilla W, Kulkarni AD, Kuppermann BD, Wheeler L, Burke J : Ocular changes after photodynamic therapy. Invest Ophthalmol Vis Sci $47: 377-385,2006$

5. Lai TY, Chan WM, Lam DS : Transient reduction in retinal function revealed by multifocal electroretinogram after photodynamic therapy. Am J Ophthalmol 137 : 826-833, 2004

6. Sho K, Takahashi K, Yamada H, Wada M, Nagai Y, Otsuji T, Nishikawa M, Mitsuma Y, Yamazaki Y, Matsumura M, Uyama M : Polypoidal choroidal vasculopathy : incidence, demographic features, and clinical characteristics. Arch Ophthalmol 121 : 1392-1396, 2003 
7. Spaide RF, Donsoff I, Lam DL, Yannuzzi LA, Jampol LM, Slakter J, Sorenson J, Freund $\mathrm{KB}$ : Treatment of polypoidal choroidal vasculopathy with photodynamic therapy. Retina $22: 529-535,2002$

8. Lee SC, Seong YS, Kim SS, Koh HJ, Kwon OW : Photodynamic therapy with verteporfin for polypoidal choroidal vasculopathy of the macula. Ophthalmologica $218:$ 193-201, 2004

9. Chan WM, Lam DS, Lai TY, Liu DT, Li KK, Yao Y, Wong TH : Photodynamic therapy with verteporfin for symptomatic polypoidal choroidal vasculopathy one year result of a prospec- tive case series. Ophthalmology $111: 1576$ 1584, 2004

10. Silva RM, Figueria J, Cachulo ML, Duarte L, Faria de Abreu JR, Cunha-Vaz JG : Polypoidal choroidal vasculopathy and photodynamic therapy with verteporfin. Graefes Arch Clin Exp Ophthalmol 243 : 973-979, 2005

11. Hirami Y, Tsujikawa A, Otani A, Yodoi Y, Aikawa H, Mandai M, Yoshimura N : Hemorrhagic complications after photodynamic therapy for polypoidal choroidal vasculopathy. Retina $27: 335-341,2007$ 